\title{
Open Source, Social Activism and "Necessary Trade-offs" in the Digital Enclosure: A Case Study of Platform Co- operative, Loomio.org
}

\author{
Sam Jackson ${ }^{*}$ and Kathleen M. Kuehn ${ }^{* *}$ \\ "Victoria University of Wellington, Wellington, New Zealand, samk.jackson123@gmail.com \\ "Victoria University of Wellington, Wellington, New Zealand, Kathleen.kuehn@vuw.ac.nz
}

\begin{abstract}
This article explores the tensions and tradeoffs facing the open source platform cooperative Loomio.org, an online tool that aims to decentralize power through deliberative decisionmaking. Combining discourse analysis with political economy, we demonstrate how Loomio's politics of resistance is built directly into the architectural design and platform structure, which invites users to participate in its development and evolution. Yet by prioritizing its social justice mission, Loomio must make certain tradeoffs around data storage and management that paradoxically threatens to compromise its wider social goals. The realities of operating an open source platform are discussed in the context of the contemporary digital economy. We argue that if platform co-operatives like Loomio are to fully realize their goals, a digital commons unencumbered by capitalism requires access to reliable, affordable and accessible alternatives to the existing Internet infrastructure.
\end{abstract}

Keywords: open source, digital commons, platform co-operativism, user-generated content, Occupy, commodification, datafication, data management, social justice movements

In 2011, a protest against economic inequalities in New York City's Zuccotti Park sparked what would become a global movement marked by similar occupations of public space worldwide. While each site within the larger "Occupy Movement" microcosm based its platform around local concerns, they collectively maintained a shared goal of flattening global political and economic distribution. Amongst other things, Occupy protestors wanted to resist the centralized, hierarchical structures of power that they saw as serving a small elite class at the expense of wider democratic and humanitarian processes.

As part of this movement, protestors created innovative ways of demonstrating democratic engagement and distributed forms of control. Social media and digital technologies played a large part in this process, connecting the global Occupy network for the purposes of sharing information, strategies or other tactics. Yet despite the movement's anti-corporate resistance, many of the technologies deployed for organizing purposes were hosted on proprietary platforms, such as Facebook, Twitter, Skype and Meetup. Over time, developers launched a number of digital tools designed to enable more democratic forms of communication over non-proprietary networks and platforms. What follows is a case study of one such development, Loomio.org, an online open source platform for consensus-based decision-making.

Borne out of the Occupy Wellington (New Zealand) movement in 2012, local activists developed Loomio out of a frustration with the lack of available tools to effectively aid in deliberative decision-making processes. A team of young developers launched the site to employ a "scalable way" for the movement's "general assembly" to inclusively deliberate on issues for the purpose of coming to group agreement. Within Occupy, the general assembly was a circle of activists who attempted to weave the ideas of the many into a singular voice (Siegfried 2014). Loomio effectively moved the general assembly online by re-asserting a communal space for discussion, offering the potential for "online tech(nology) to go beyond mobilization and into sustained collective action" (Krause 2014). The task of collecting or hearing each view, aggregating and re-broadcasting (at times through a "human microphone") proved to be an unwieldy and exhausting process. The software essentially functioned as a social network enabling groups to interact through thread-based conversations. After a cer- 
tain amount of conversation, topic threads progress to a proposal stage; more deliberation and discussion then give way to a participant vote on the resolution. Thus, Loomio attempts to rationalize the political process of the general assembly in a more efficient and inclusive way. As informed by the politics of Occupy, Loomio continues as a digital space designed to alter current hierarchies of power within specific organizations and greater society (Krause 2015).

Loomio's developers also intentionally worked to subvert proprietary forms of communication through its co-operative structure and open source model. With a secondary goal of enlarging the "digital commons," the ideological struggle first initiated by Occupy found new enunciation in Loomio's organizational politics and its software's architectural design. The goal of creating "commonly held resources that benefit all" (Krause 2015b) speaks to the fact that a dominant proportion of web-based platforms and services, as well as the infrastructure that sustain them, are owned and controlled by private companies and commercial interests. As a result, the contemporary digital landscape is one where users must trade their personal data like currency for access to most contemporary communication services and technologies (van Dijk 2014). In an explicit rejection of this trade-off-and much like Occupy's primary goals, as well-Loomio's co-operative and open source model aims to place resources back into the commons by shifting ownership from corporate control to user control.

What follows is an examination of these tensions that analyses how Loomio is able to prioritise its social justice mission as a platform co-op while navigating the commercial imperatives of the commercial web. The central research question guiding our analysis is: How does Loomio, as an open source platform co-operative, work to overcome or complicate the commodified structure of the contemporary web? We posit that despite growing privatization, the Internet continues to be leveraged to (re)claim a digital commons always under the threat of undermining economic constraints. While these findings are not generalizable to the broader picture of open source or the contemporary digital economy, they do hint at some of the problems associated with an open source co-op's struggle to protect and expand the digital commons within a structural context of increasing privatisation and commodification.

By combining discourse analysis with political economy, we offer a critical reading of the limitations that a largely privatised digital economy places on the organization's attempt to enlarge the digital commons. At the same time, our findings also acknowledge Loomio's agency in creating resistance to the model that encloses them. Borrowing from Robert Gehl's (2010) understanding of the web as "surface versus depth," we argue that the shift towards datafication and the wider commercialization of the web make up an important material base that problematizes Loomio's ability to function as an anti-capitalist commons-based resource. These findings are then discussed in relation to the implications this has for the future of open source.

\section{The Political Economy of "Web 2.0"}

Scholarly and popular debates about "web 2.0" and the state of the digital commons are often constructed in binary terms: narratives of empowerment and democracy on one end, surveillance, exploitation and commodification on the other. Much of the critiques and celebrations focus on the affordances and limitations that web-based interactivity offers for expression and participation, particularly via applications that enable the writing of cultural production. Technological advancements since the mid-2000s have meant that the lack of any necessary computing or coding skills no longer precludes most people from producing online content. This flattening in use has enabled what Lawrence Lessig (2006) identified as a shift to "read/write culture," where the web user is reconstructed as web "produser" (Bruns 2008; Ritzer and Jurgenson 2010). Online companies like Facebook, Amazon, and WordPress offer a model of creation that both allows and demands user interactivity; these sites supply the platform, while users fill in the content via available tools and functions. Advocates of the so-called "social web" have argued that user-generated content broadens the depth of social and creative contact between people, thus enabling more equally dispersed forms of user power (Jenkins 2006; O'Reilly 2004). For Manuel Castells (2011), the social web has the 
capacity to create a "digital commons;" that is, a publicly-owned space for free expression. Importantly for Castells, "publicly owned" requires that users also have the ability to construct these platforms as relevant to their needs.

The democratizing promise of such interactivity, however, has also been accused of ideological obfuscation (Andrejevic 2011). The commercial advertising regime that underpins digital technologies and platforms, for example, ensures for critics like Mark Andrejevic that power continues to resist real democratization. The commodification of user expressions by contemporary data gathering practices arguably undermines the digital commons' capacity to function as an open space free from the demands and influence of capital. In this more critical perspective, users are encouraged into a superficial engagement with the means of production as their creative exploits are captured as surplus economic value; hence, the locus of power remains with large corporations (Gehl 2010). While users may be empowered to coconstruct a more diversified and sharable cultural landscape, the realization of a digital commons is undermined by an economic paradigm based on a basic privacy-forconvenience transaction. That is, while web users can freely write, record or share on the surface of the website, the cost of this convenience typically requires the surrender and sale of personal data.

Gehl (2010) illustrates this transaction as one of surface versus depth. As users skate along the "surface level" of the web they fill in the "ghostly frames" of the website, make social connections, remix content and "process digital artefacts" (24). Beneath the surfacewhat Gehl calls the "depth"-lies the code that make these surface activities possible. Gehl argues that the takeover of web infrastructure by capital has allowed corporations to capture this production and deny users the ability to determine how it is configured and used. Perhaps this is the clearest example of capital's infringement on a more decentralized web as it indicates the shift from a common space (as one owned and operated by users) to a public space (one curated by capital but populated by users).

This problem of surface versus depth is thus in part created by the dominant proprietary systems used by software companies that concentrate the control and ownership of web infrastructure and software in corporate hands. Despite generating surplus value for these digital firms, users are effectively denied agency over much of the production context; this includes access to the code and algorithms that sort and target users for marketing purposes, transparency into how user data is collected, stored and used, organizational decisions about maximizing profits and so on. The dichotomy of surface versus depth is thus a useful framework for explaining the basic economics of the contemporary social web and the methods by which new media capitalists lock out users from their own intellectual property. In this case, however, the distinction between surface and depth is useful for illustrating how the web's material base-particularly the role of third party services-compromise Loomio's ability to create non-exploitative, pro-user software in the digital commons.

\section{Open Source and the Digital Commons}

Importantly, the subjugation of web users does not occur uncontested but necessarily breeds resistance. As the Occupy movement demonstrated, resisting hegemonic forms of control is part of the social fabric of everyday life (Ball 2006). In the digital sphere, the open source movement is one method by which programmers have attempted to use digital tools and web architecture to push back against its enclosure. Characterized by Eric Raymond $(1999,27)$ as a "bazaar-style development model," open source weaves a multiplicity of designers into the web development process. Importantly, this iterative model threatens to undermine proprietary claims over software by allowing for the free exchange of ideas and development by users. As a system of non-proprietary software production that relies upon and privileges user creation, open source reconfigures the use of resources around the "right to distribute" rather than the "right to exclude" (Weber 2005, 6). This form of production both utilizes user participation and engenders the rights of the user into its organizational structure. Open source allows programmers and coders get beyond the surface to alter fundamental aspects of the web's depth (Gehl 2010). 
Celebratory discourses about the counter-hegemonic possibilities of open source frame it as an attempt to free the user - especially the code-literate user - from the machinations of capital (Weber 2005). It is in handing over the network's design and control to users that allows a reading of resistance to be mapped onto the social web. Here, power ostensibly shifts away from new media capitalists and into the hands of users/producers. Framed as a mode of resistance, open source software thus attempts to subvert some of the web's more common exploitation practices (Gehl 2010).

Open source programming exemplifies-as it also aims to expand-the idea of a digital information commons; that is, a publicly-owned space that facilitates public discussion and cultural production on the web (Benkler 2006, 60). By definition, open source's commitment to making code and non-proprietary licensing models accessible can be understood as part of this commons. Built on the principles of democracy and fairness, a digital commons arguably allows for greater user expression and rights (Andrejevic 2011). This definition necessarily expands and contextualizes traditional ideas of the public sphere to include the audiovisual and social creations that suffuse the online experience.

However, while the digital commons provides a highly visible and expanded conception of public space, it is not a space completely free from corporate control. Certainly, open source software is used by both commercial and grassroots organizations, and is dependent on a pool of free and collaborative labour. Phoebe Moore and Paul Taylor (2009), for example, argue that the free and open source movement can be read as a form of self-exploitation; from this view, individuals take responsibility for their own software development, training and/or upskilling for future entry into the marketplace or securing jobs with high-profile tech firms (see also Carillo and Okali 2008). In some contexts, the digital commons might be seen as its own enclosure in which web users/producers remain separated from the value of their production (Andrejevic 2012). Yet open source does present an alternative to the dominant logics of copyright and commodification that hold a range of possibilities proprietary production models do not.

\section{Platform Co-operatives}

Much like open source, platform co-ops similarly exemplify commons-based objectives of democratizing participation, ownership and decision-making processes. Broadly speaking, worker co-operatives are organisations collectively owned, directed and controlled by the people working in them (Sandoval 2016). Their aim is to create and maintain sustainable jobs that humanize work conditions and improve the quality of life for worker-members. Worker co-ops have a long history, and not all have an explicit political agenda. However, many co-ops, including platform co-ops, re-emerge at present as exemplars of the New Left's tactics at "horizontalism," communities constructed as local antagonisms to the dominant neoliberal global order (Srnicek and Williams 2015, 47). As a radical alternative to capitalism, co-ops aspire to more egalitarian, autonomous, secure, collectively-minded and productive workplaces. Viewed as an antidote or alternative to economic precarity and the individualization of work, radical co-ops are an economic response to the political steps taken by movements like Occupy that aim to destabilize capitalist-driven inequalities.

For Trebor Scholz (2016), platform co-ops hold the potential to contest the "sharing economy's" growing regime of on-demand services of companies like Mechanical Turk, Upwork, Yelp, Crowdflower, Uber or TaskRabbit and their low-waged, contingent or freelance work arrangements. Much like these companies, platform co-ops also aim to create new efficiencies, yet they do so by offering comparatively sustainable employment, social benefits and job protections. By eschewing automated surveillance metrics or rationalization techniques that 'densify labor' for quick profit returns (Huws 2014), platform co-operativism thus provides a way of thinking about "how the Internet could be owned and governed differently and how solidarity could be strengthened in the process" (Scholz 2016, 10).

As a form of "pre-figurative politics," collective enterprises like platform co-ops put into practice social alternatives for economic organization by recognizing that the struggle towards alternative futures is grounded in a politics of the present. Mathijs van de Sande de- 
fines prefiguration as a practice concerned with bringing utopian goals to the "here and now", where the "temporal distinction between the struggle in the present toward a goal in the future (is removed)" (2015, 188-189). However, like other pre-figurative political projects, coopts demonstrate alternative possibilities through practice even as they "are constrained by the very reality they are trying to overcome" (Sandoval 2016, 58). As Nick Srnicek and Alex Williams argue $(2015,35)$, "prefigurative communities require a variety of logistical supports, including housing, food, sanitation, healthcare, and legal advice. Most of this does not come from within the prefigurative community, but instead relies upon existing capitalist networks." These capitalist networks ensure co-ops are constrained by market values and the need for capital (e.g., financing, overhead costs) that in turn, subject workers to the many precarities associated with traditional waged labour (Sandoval 2016, 58). Co-operatives are thus broadly criticized for ignoring or being unable to manage the tensions and trade-offs inherent to a collective enterprise prefigured by capitalism.

The capacity for co-ops to increase worker happiness, wealth and productivity has also been critiqued for expanding and improving capitalism, not resisting or confronting it (Sandoval 2016). In this sense, co-ops map neatly onto neoliberal discourses of personal responsibility and self-empowerment. They are framed as a private solution to resolving many of the pressing social, economic or political issues that are likely a byproduct of neoliberal capitalism in the first place. Worker-owned and directed enterprises provide a space where workers and communities alike can help themselves instead of relying on government officials, regulators or the workplace to address the problems they face. Capitalism's appropriation of cooperative values only intensifies the challenges co-operative organizations already face in reconciling their political objectives with the economic realities of the market.

\section{Methods}

This research combines cultural analysis with political economy to understand how Loomio's commons-based mission as a platform co-op is disrupted and limited by the web's commercial imperatives. This hybrid methodological approach is informed by lan Goodwin's (2012) use of discourse analysis and political economy to understand web-based modes of resistance, as well as Zizi Papacharissi's (2009) discourse analysis of virtual geographies that examines and compares surface and depth.

The discourse analysis of Loomio draws from an investigation of the site's architecture, the company's co-operative structure, press statements and the Loomio blog to understand how the site's ideological motives to decentralize power on the web are simultaneously actualized and undermined. This analysis also draws from in-depth interviews conducted with four members of Loomio's management team. Interviews lasting approximately one hour each were conducted, recorded and transcribed by the first author in 2015. Interview subjects are referred to throughout the findings only as "worker-member" in order to maintain confidentiality. Considering the large amount of collected data, interviews were analyzed by focusing on the themes of resistance to commodification and the limitations placed upon Loomio by the political economy of the contemporary web. These interviews lend themselves to linking a cultural analysis of Loomio discourse with the wider political economic context in which it operates to better illustrate the range of agency and constraints the organisation faces as it attempts to enlarge the digital commons.

\section{A Discourse Analysis of Loomio}

As previously described, Loomio functions on an open source platform that aims to establish a digital commons by leveraging the web's decentralized and interactive affordances. The company's founders consider Loomio a tool that better enables and facilitates discourse around deliberative principles; their primary goal is to construct group decision-making practices as a more egalitarian, consensus driven affair. In their words, Loomio is a "missiondriven organisation with a social purpose at our core: Loomio exists to make it easy for anyone, anywhere, to participate in decisions that affect their lives" (Loomio 2016). Much like the Occupy movement, the company's social mission of empowering organizations and commu- 
nities "to turn discussion into action" is founded on a belief that bottom-up processes made through community interaction leads to better, more representative democracy. The site is explicitly based on a model that privileges inclusion and subverts the dominant hierarchies and decision-making processes characteristic of many businesses and NGOs. The software has been used to this end by a wide range of corporations, government and non-profit agencies, community groups, political activists and other organisations worldwide. Loomio users range from the Spanish political party Podemos, Wellington's City Council and the Welsh government's National Assembly for discussing and voting on various proposals with citizens, to the New England Institute of Technology as a replacement for office meetings. A German housing collective uses Loomio to deliberate on various decisions affecting its 200 members before bringing a vote to general assembly. The French innovation camp 'POC21' has used Loomio to collaborate on open source eco-hacking practices, while NYC's 'Trusty Amigos' pet care co-op has also used Loomio for proposing, deliberating and developing the co-op's business decisions (Loomio, 2016).

The enabling role of Loomio's software is only one side of the coin; the company's offline co-operative work structure also intends to serve as an exemplary model of what a successful Loomio group thread might look like. As one worker-member claimed, the relationship between open source and co-operativism is "totally central" to their mission: "The cooperative structure is really about collective ownership and collective governance, which are really strong elements of open source, as well." Another owner described Loomio as strategically built on the pre-figurative ideals of diffused, decentralized power. He views the cooperative model as one method of achieving that aim.

I think that mode of [economic] organising is super powerful, it outperforms the coercive mode and it's pre-figurative. It's pre-figurative in the sense that I want to live in a world [where] no one has power over anyone else, and to get that point, I want to practice living that way now.

Within the organization, the role of each worker-member is fluid and prone to change. There is no traditional managerial hierarchy. Instead, Loomio invented a temporary, rotating "coordinator" position held by at least two members simultaneously to oversee "big picture" operations for a given period of time. The role rotates regularly and involves facilitation, support and taking leadership in the delegation of responsibility to other co-op worker-members. The coordinators function much like a senior leadership team but carry no more power than any other co-op role. As part of Loomio's commitment to worker self-determination, roles are reviewed quarterly and always up for discussion. As their website explains, "Mutually agreed structure for our work helps us to be more productive and happier" (Loomio 2016).

Workers have access to almost all of the company's information and are involved in decisions made about long-term strategy, quarterly plan, and daily work. Some responsibilities, such as setting the quarterly budget, are reserved for those formally recognized as workermembers. Becoming an owner of the Loomio co-op is open to anyone who has worked there for a year and can commit to at least one additional year into the future.

While Loomio worker-members make decisions collectively, they are oftentimes extended to include the input of Loomio users, as well. Contributors to the open source model are invited to "pick up work the core team doesn't have capacity for," a process the Loomio team has tried to integrate within the site's overall vision (Krause 2014b). Governance at Loomio is thus an iterative and collaborative process between paid workers and unpaid users; at least discursively, the Loomio (paid) team actively aims to avoid recreating the conditions of alienation and exploitation. As described, Loomio's "capacity is built on a sense of ownership among our membership. Loomio is fast and flexible, so we can give more volunteers a stake, and make better informed decisions" (Loomio 2016).

The co-operative model is thus one that mimics the technosocial affordances of the software itself. Loomio members argue the importance of allowing different and diverging voices into the conversation, allowing for what they see as the development of multiple leaders and innovators: 
How can we rework societal power structures that waste so much human potential by limiting human freedom? How can we structure our communities, cities, companies, and societies so everyone can lead? What really creates marginalization and how do we counteract it? [...] If the pathway to leadership isn't accessible to everyone, it means there are seeds left unsprouted (Krause 2015).

Loomio thus uses its co-operative model to navigate away from what they see as the marginalizing power structures of traditional business; it does this not only through its software, but by structuring its own organizational leadership in a way that taps into the potential of everyday people. Much like the celebratory discourses of web 2.0, Loomio constructs "user empowerment" as both a means and an end..

As previously noted, Loomio's software utilizes technology in a manner consistent with the company's ideological origins and values: "Openness is a defining aspect of everything Loomio is about. Our mission is to enable a more open world, where transparency and accessibility in decision-making is the new normal" (Krause 2015b). Yet not everything on Loomio is open. While anyone with digital access can participate in a Loomio discussion, threads are often closed or private to ensure group decisions are being deliberated by those directly affected. This feature allows threads to remain localized as opposed to, for example, allowing a business owner in the United States to participate in City Council deliberations in New Zealand.

Most of Loomio's features are, however, open to public contributions; this includes group threads dedicated to discussing Loomio's functionality, access to the software's source code and site features. Public group threads allow any Loomio user concerned with the software's development to participate in discussions aimed at generating resolutions. For example, a public thread dedicated to language translation issues on Loomio illustrates the processes by which Loomio worker-members and users engage in deliberative decision-making to solve problems. The thread entitled, "Allow Comments and Discussions to be Translated" starts with one Loomio user named 'Pirate Praveen' proposing the following problem about Loomio's translation services:

In a recent discussion one member had to use their mother tongue so that they can clearly express their idea-But that would automatically exclude people who speak other languages but can understand English. In this case I manually translated all comments in Malayalam to English and posted as my comments. I would like [sic] loomio to be able to allow this as a feature i.e., each text content needs to be translatable so that anyone can offer translations and people can choose their preferred languages to communicate.

Other users, including Loomio worker-members, then joined the thread's discussion to collectively problem-solve the initial proposal. User @jameskiesal, an open source developer unaffiliated with Loomio, quickly built the proposed plugin to solve the translation problem.

By providing free and open access to the "depth" of its platform (i.e., code), Loomio establishes a shared space that pools the resources of disparate users to enhance the commons' functionality. Another way this occurs is by enabling users to "fork" Loomio on GitHub. In programming language, to "fork" means to take and use software code for one's own ends. GitHub is a web-based repository hosting service that offers a graphical interface to better facilitate dialogue between developers. Once on GitHub, a user can pick a Loomio project on which to contribute code. The process of forking creates a dynamic interface between users and Loomio as the code provides the means by which users restructure Loomio to meet their needs.

Group threads and GitHub interactions are two ways that provide users insight into program code and operations; more importantly they allow for critique, education, and a blurring of the user/producer divide. Both aim to empower users with both a voice and the tools needed to redress issues that arise over the site's general functionality. While these resolutions depend, of course, upon the "free labour" of users, it is this labour pool that also enables the quick and efficient delivery of a non-proprietary solution useful to the wider Loomio 
community. Unlike proprietary production networks, Loomio does not retain the rights to user modifications, dictate the terms of user developments or exclude users from making decisions that impact upon the site's evolution or use. So while Loomio users certainly take up the labour of the site's evolution, we argue this labour is not valorized through a Marxian model of exploitation and alienation. Rather, the generation of surplus value relies upon the realization of deliberative principles and action through tools and processes over which users have input, access and control. Moreover, user data is not sold or reinvested as capital. This is a significant departure from the way other web 2.0 critiques speak of alienation as an estrangement from one's labour, output, other workers/users, management, or themselves (Fuchs 2013; Kuehn and Corrigan 2013).

This is not to say, however, that Loomio's anti-commodification stance is totally free from systems of capture and enclosure. While interventions into Loomio's development by users certainly limit the rationalizing tendencies of many web firms, there remain a number of factors that undermine total independence from the constraints of capital. The following section places Loomio back within the political economy of the web to illustrate the compromises and tensions it faces in the desire to operate outside the enclosure model of digital capitalism.

\section{A Political Economy of Loomio: Web 2.0 as Enclosure}

New media capitalists have created an online ecosystem that makes it increasingly difficult to situate knowledge production within a digital commons. The political economic context of the contemporary web-one based on the rationalization and commodification of user activities-structures an environment antithetical to Loomio's wider mission of decentralizing power. As one worker-member explained:

The decision to make Loomio open source was totally a reflection of that line of reasoning, the more that we can do to create public resources, public infrastructure that can't be captured by purely private interests, the better we will be collectively.

Another Loomio member echoed Andrejevic's (2012) critique of the digital enclosure in his analysis of the current climate of web software: "There is this really rapid enclosure of the common space, the knowledge commons, that the Internet was kind of predicated on." However, while Loomio is explicitly "against the flow of rationalization...the challenge of rationalization is a big one."

Of particular challenge is raising the necessary funds required to maintain and preserve Loomio's basic infrastructure within the commons in ways that do not depend on the exploitation or commodification of its users. The following section illustrates the depth of this challenge and the way that operating within a largely privatized digital enclosure threatens to compromise Loomio's social mission.

\subsection{Revenue Model}

Loomio operates through a diverse and complicated process of revenue gathering that depends on a tripartite arrangement of charity-based investment, payment for consultation work and optional payment for the service itself. As having a social impact is Loomio's primary goal, the site aims to create surplus, not to maximize profits. For 2014-2015, Loomio raised $\$ 124,984$ in donations through a crowdfunded campaign. Funding for 2015-2016 derived from what another worker-member described as "values-aligned individuals who can make a significant investment for delivering a social impact rather than a financial return." Another revenue stream comes from consultation work, which involves Loomio worker-members providing training and consultation for organizations, including councils and large businesses. This work is often about helping businesses use Loomio more effectively for the purposes of creating more inclusive and constructive decision-making practices, or engaging in more collaborative processes. 
Loomio's other revenue source is an optional pay-for-access plan. This model asks those with a budget to pay for access to subsidize Loomio's use by charities and social value enterprises. Commenting on the complexity of this revenue model, a Loomio worker-member stated: "We have been looking for ways to get people to pay for using the software without preventing people without money to use the software. And it's easy to say and it's hard to do." The unusual nature of its revenue streams requires that Loomio make its payment plan transparent through conversation and education. In this sense, payment is discursively constructed to users as a "donation" that preserves its social mission by helping keep Loomio in the commons.

Loomio's array of revenue-generating procedures is a direct result of their refusal to engage with venture capital and datafication, two dominant funding approaches for most web startups. Like all co-ops, private external funding compromises collective ownership as its priorities must then re-align to those of its shareholders. Loomio critiques venture capital as compromising the service that its software can deliver, especially in regards to data security. As one worker-member explained, avoiding venture capital is crucial to Loomio's agency. As venture capital investors expect a maximization of profit, this requisite insists upon quarterly returns much higher than they are at present; they also require monetization practices that would compromise some of Loomio's primary commitments, such as access equality or freedom from commodification. Loomio's oppositional stance towards venture capital funding exemplifies platform co-operativism's resistance to capitalism more broadly.

\subsection{Data Management}

Another key form of capture by private interests Loomio resists is the process of "datafication:" the collection, storage, usage and/or sale of user data for the purposes of profit generation (van Dijck 2014). Datafication is the primary means by which most contemporary web firms now turn a profit. Loomio worker-members explicitly rejected this quantification of social action, singling it out as a means of revenue-generation fundamentally at odds with its core social mission. Speaking to this point, the organization has promised to never sell user data; as reassured by one worker-member: "We've explicitly said that we won't sell [data]. We've written that into our privacy policy, and it's implicitly in our constitution, because our constitution explains [that] we prioritise our social mission over any kind of profit motive."

Despite this stance, data management remains a problem for Loomio. The storage of basic user data is required for ensuring threads remain active, general efficiencies and other basic operations. However, the Loomio team has not created any profitgenerating incentives around data. One owner explained how Loomio's position on data management is distinct from that of Facebook, for instance:

Facebook is a big contributor to open source technologies, Google also. But they've got end user licenses and practices which are about maintaining market share by manipulating and holding onto and choosing what they do with the user data that people give them.

By nature of the activities occurring on Loomio, the software obviously produces massive amounts of content and metadata; however, Loomio neither sells nor makes this data available for public or private use. Moreover, most conversations between groups are set to private, so the opportunity to offer access is also limited. As a worker-member explained, "We're holding that data, and we haven't even really worked out what it means to share that data fairly." This, however, problematizes Loomio's attempt to combat issues of privacy and control on the web. Acknowledging the potential problems data storage poses, another worker-member suggested peer-to-peer storage as a potential future solution. The implications are yet unknown, however, as this is not yet a practiced mode of storage.

In the absence of venture capital and other data-generating revenue, Loomio must meet its basic overhead costs by making tough calls about where to allocate funds. What gets cut or deprioritized is thus one of the more complicated tensions the Loomio team faces. Interviews identified data security as one of Loomio's most pressing and troubling problems. Spe- 
cifically, their overreliance on third party providers and storage centralization as cost-cutting mechanisms has meant that data security takes a back seat to Loomio's main focus on software functionality. Paradoxically, data security takes a backseat to Loomio's goal of putting principles over profit, even as this decision creates the very types of compromise its software emphasis aims to avoid.

One worker-member described Loomio's data security measures as following industrystandard "best practice" with a "fairly standard hosting arrangement, fairly standard encryption [but] nothing super secure." Another explained that data security is taken very seriously, yet cited the lack of funding and expertise to adequately deal with data management. The employees expressed particular discomfort and anxiety over Loomio's centralization of data, which currently sits on the company's single operating server. Expressing regret over what he sees as Loomio's substandard security protections, one worker explained that Loomio would ideally like "to be able to provide people with a really secure service that split the big huge data storage into much smaller ones." Loomio generally views its centralized data storage as a problem, but one exacerbated by the limitations of operating an open source model that resists data exploitation and venture capital.

A second concern about data security involves the company's outsourcing of resources to third parties. The relatively cheap hiring of third-party servers allows Loomio to save revenue and focus their resources on decentralizing knowledge production. However, prioritizing software development at the expense of other commitments thus requires Loomio outsource some of its essential services; in turn, this decision has considerable implications for Loomio's goal of commons-orientated decision-making software. For example, Loomio outsources its server space to the American firm Heroku, which allows companies to host websites through Amazon's cloud platform at a fraction of what it would cost for Loomio to build and run its own server. While Loomio worker-members believe that Heroku respects private data as much it can, there is also an awareness amongst the Loomio team that this data is being hosted offshore and thus vulnerable to collection and mining.

Referring specifically to state surveillance and the kinds of government intercept programs revealed by Edward Snowden, one owner explained, "If the NSA has a back door into your central server, that's a problem that you have to manage." Considering the sensitivity of much of the user data on Loomio, the implications of this compromise are far reaching. For example, given the large number of activists and social justice groups that use Loomio around the world the potential capture of this data by government or corporate power has troubling ramifications, particularly for those in non-democratic countries.

The fact that we are hosted on servers that obey government surveillance requests, and that we use services which share user metadata, I think it makes it quite clear that we are not a good place for activists who are trying to upset those organizations. However, we really do want those kind of groups to be able to do things with our tool, which is one of the reasons why open source is so great. We can at least provide them with instructions, and software to run it in a way which is free of those kind of information leaks.

Server space is not, however, the only third-party service employed by Loomio to streamline operations. Microsoft Bing and Cloud Fare are also used. Bing, for example tracks metadata every time a user clicks the "translate" button. Again, while Loomio sees this as "not ideal," they see the opportunity to cut down on communication barriers as a necessary tradeoff. One worker-member explained that,

third parties drastically improve the user experience and improve the value that people are getting, and reduce our costs, and that's how the market works. So Cloud Fare got really good at doing what Cloud Fare does. And Loomio gets really good at what Loomio does.

He went on to indicate the tradeoff that this decision represents is a continual balancing act between efficiency and data security. 
So you've only got a small amount of resource, so how do we spend it? Oh, we'll spend it on making the decision making functionality work extremely well, and then [...] we're working with all of these third parties that are known to also collaborate with the Five Eyes [mass surveillance] spy programs, and that doesn't fit with our values; there has to come a time where, Okay, the functionality is good enough and we're now going to take the time to invest in security and privacy.

Thus Loomio's dependence on third parties is seen as an uneasy tradeoff, one that drastically improves the functionality of the decision-making software as it simultaneously conflicts with their mission to provide a communicative tool outside the reach of government surveillance and corporate power.

Loomio attempts to manage its data security problem through its transparency policy. One way this occurs is through hosted conversations on Loomio that attempt to inform and solicit feedback from users:

There is a conversation live right now about third party services that we use and how that affects your privacy and stuff like that, some of the outcomes of that conversation is that we have changed some of our behavior to prioritise peoples' privacy over our efficiency and that's just, like, the result of having a conversation.

The thread to which the interviewee referred, [sic] "Third parties Used in Loomio.orgImplications for users", involved a heated exchange between Loomio worker-members and concerned users about third parties contracted to perform some of the software's more crucial services. One user, @strypey, complained that Loomio's use of proprietary third parties like Cloud Fare discriminates against anonymous users as a direct competitor of the open source web browser TOR (TOR allows users to access the web anonymously in order to circumvent data capture and surveillance). In response, a Loomio worker clarified Loomio's use of third parties on the site's blog in an attempt to outline the ways in which user data could in fact be compromised. Loomio later updated the thread by revealing they had "discontinued our use of Heap Analytics today, so we can strike one more service off the list of third parties in use on loomio.org!" Listening and adapting to user suggestions and critiques signals another example of how Loomio attempts to empower users through conversation and involvement in the development process; in this case, Loomio's core values of deliberation informed how they have dealt with data security and management.

Loomio views their handling of data as in terms of stewardship, not profit maximization. One worker-member explained, "We know we've got a certain responsibility....we are the stewards of this huge amount of data, and we need to go above and beyond to look after the security of it." Stewardship rather than ownership signals another different approach Loomio takes to other web 2.0 firms; their focus on storing rather than mining, analyzing or selling data indicates their attempt to create a system of revenue that opposes the commodification of user agency. But this approach requires a difficult balancing act in order to make Loomio financially viable outside datafication processes. As one worker-member admitted, "It's tricky, there is some commodification there, without a doubt. But it's limited."

Loomio faces considerable difficulties "doing business" in an increasingly privatized system and space. As demonstrated, prioritizing their social mission requires carefully negotiating the economic realities that threaten to compromise this mission. This struggle illustrates the pervasive nature of the digital enclosure and the seeming impossibility of creating software wholly removed from the constraints of capitalism.

\section{Assessing the Trade-off}

In order for co-opts to redistribute income or social benefits to workers requires having successfully navigated and competed in the capitalist market. As Marisol Sandoval $(2016,63)$ points out, co-op members can decide how internal functions such as ownership and decision-making processes take place, but "they cannot overcome the dependencies that result from operating within a capitalist economic system." Loomio's external dependencies are 
primarily financial and technological. Financing is required for the purchase of hardware, software, server space and other overhead costs. But in order to reduce the dependency on financing, Loomio must also outsource some of its functions as well, namely storage space.

So even though Loomio is discursively committed to good data management and security and has an expressed preference for "freedom- and privacy-respecting tools," it must sacrifice some aspects of control for economic reasons.

We would be worse off if we didn't [outsource to third parties]. So we are actively making this tradeoff with our user data in order to provide a better service, in the hopes of having more social good come out of it. But it is a really thought provoking tradeoff that needs to be considered very carefully.

This "trade-off" does not so much signal a disregard for data management so much as the team's belief in Loomio's capacity to promote democratic governance. As one owner stated, "The more financial security we have, the more we'll be able to invest in building and using open source free software." The interviews justified the prioritizing of Loomio's mission as one that takes a long-term view:

What are we going to spend that last little trickle of money on, it's probably not going to be hosting a conversation with our users about privacy. It's probably going to be on making this tool work extremely well, and resiliently. So if our company falls over, then at least people still have the tool.

Hence Loomio prioritizes the basic function of its software in the hopes of creating more lasting change; as indicated, the problem of data security comes second to the effectiveness of the tool.

A case study of Loomio illustrates the limitations of Gehl's (2010) claim that access to the depth of the program can foster user agency and empowerment. Yet under this surface, the infrastructure that websites like Loomio depend upon (e.g. private servers, third party services), exemplifies a model of enclosure based on an encroaching privatization of the digital realm. As Tiziana Terranova (2004) has argued, it is nearly impossible for open source software to operate completely outside the capitalist imperatives of the web, even as a free, open source co-operative model. Loomio's politics about user privacy and empowerment may be oppositional to dominant market discourses, but economic realities require a negotiated stance that place Loomio users in a position vulnerable to the goals of capital. Evinced by one worker-member who admitted Loomio needs to do a better job explaining this potential co-option of data by third parties to its users: "We haven't solved data at all. We haven't come close to solving the privatisation of data [...] I don't know what solving the privatisation of data really looks like." While no stranger to web development or Internet infrastructure, his statement indicates the challenges facing web firm that want to circumvent the complex systems of capture and enclosure. The limitations that both worker co-ops and open source platforms place on revenue gathering ensures that global pre-figurative political projects like Loomio remain susceptible to the dehumanizing and exploitative dynamics of capitalist systems.

Users on Loomio are therefore asked to be mindful of their use of Loomio; they are also encouraged to create a private instance of the site when they can in order to keep Loomio off the Internet entirely. This delegation of security to the user, however, means that the user sits in a somewhat precarious position on Loomio. Users, of course, are given methods to overcome this commodification, but this means that data security management predominantly falls on them. In practice, methods like forking depend on a reasonably high level of programing knowledge and ability. Rather than a public community good, privacy becomes a "luxury commodity" afforded to those with the digital literacies and resources to obtain it (Papacharissi 2010). Offloading the responsibility of insulating oneself against surveillance, datafication or other privacy invasions inherently contradicts open source and co-operative goals of decentralizing power. Privacy thus becomes yet another social stratifier that disenfranchises those who often have the most to lose. 


\section{Conclusion}

This article has explored some of the tensions and tradeoffs facing an open source organization dedicated to universal accessibility and hierarchical resistance. On Loomio, this politics of resistance is built directly into the architecture, design and structure of its platform as well as its social mission. Its open source model freely provides access to the software's source code, which welcomes users to participate in its development and evolution. In addition to the interactive features designed to combat top down decision-making, Loomio also involves and responds to users in discussions about its software's functionality. As an embodiment of the Occupy movement's democratic politics, Loomio can be understood as a pre-figurative political project. Its co-operative structure presents an economic alternative to coercive work models embodied in the platform itself, which provides a means of usurping dominant modes of decision-making and control.

However, a closer look at software infrastructure demonstrates the difficulty that the contemporary forces of privatization create for a web firm aiming to exist outside a capitalist structure. While a site like Loomio challenges capitalist principles of ownership, decision power and worker exploitation "the legal structures available and the need to compete on capitalist markets tie worker co-ops to the capitalist system" (Sandoval 2016, 64). While open source is often framed as a form of hegemonic resistance to the web's proprietary model, the relationship between Loomio and commercial third parties complicate this picture. As demonstrated, the rejection of datafication, venture capital or compulsory payment models allow Loomio to retain its values, uncompromised by capital, in order to build software in the digital commons. But at the same time, Loomio also remains tethered to a number of proprietary third parties whose cheap resourcing make this mission possible.

While Loomio's open source model allows data security to be partially managed by users themselves, this offloading privileges those with higher levels of digital literacy. In this instance, privacy is reinforced as a luxury commodity on Loomio, intensifying the social stratification of its user base. This, of course, has particularly troubling ramifications for social justice missions. Speaking to the metadata sharing practices common amongst the third party services Loomio uses, the team has had to acknowledge that these decisions can compromise the work of activist groups trying to upset, protest or disrupt those organizations.

Loomio provides a useful case study for illuminating the paradoxical nature of the contemporary digital economy. It demonstrates how co-ops and open source remain linked to corporate capitalism even as they aim to create spaces outside corporate control. While open source allows Loomio to sidestep certain issues of data security, the delegation of security to users threatens to reproduce the same kind of hierarchies and divisions its software wants to ameliorate. Yet it is a trade-off Loomio makes in the hopes of facilitating much larger and long-term social changes. By combining cultural and political economic analysis, we have attempted to show the limits of open source while at the same time acknowledging the agency that both Loomio and users nonetheless command.

Just as Occupy pushed back against the corporate political economy, so too does Loomio push against the tide of an increasingly privatised web. And much like Occupy, resisting a commercial Internet requires expanding the digital commons on a similarly diffused but networked solidarity. In line with Scholz, we argue that "The fight for privacy and the struggle for higher wages of crowd workers are important but cooperative ownership models of the Internet would address many of these issues" $(2016,10)$. It is possible that the growth of platform co-operatives and open source free software are two ways forward in resolving the current trade-offs co-ops like Loomio face, while paving the way towards fairer work arrangements and, possibly, a more democratic Internet.

As demonstrated, Loomio's rejection of private third parties is desired but currently infeasible. Severing ties with private data storage firms, translation services or other commercial providers first requires that comparable alternatives exist. This means building a digital economy in its own right, where open source free software options are more readily available for other co-ops to resource. As one worker-member described, this vision for the future Internet means that open source free software would "need to have extremely good architec- 
ture, accessibility, documentation, and user experience design" in order to compete "with venture-capital funded giants" like Amazon, Bing and Google. Loomio itself provides the space for start-ups to organize as co-ops. Its whole purpose is to engage in collaborative decision-making and facilitating non-hierarchical structures. Loomio is not only an exemplary co-operative model, but provides the platform on which new co-ops - and thus the future Internet - can be conceived and built.

To get here, however, is not solely up to Loomio, of course. Expanding the digital commons requires people willing to create start-ups that are motivated by a people-centred Internet over a profit-centered Internet. It also requires a protective legal framework for cooperative firms to be put in place, and a regulatory environment free of policy preferences that continue to favour more traditional forms of economic organization. Platform cooperativism alone will not dismantle capitalism, but as a pre-figurative political project it provides the requisite seeds of change for new alternatives to emerge.

While Loomio attempts to construct a democratic space through its free and open source platform, these affordances are continuously under threat. If the current commercial model of the digital economy is unable to facilitate the large-scale change that Loomio hopes to see, then the expansion and protection of commons-based pre-figurative politics remains as an important and timely activity as ever. If platform co-ops like Loomio are to fully realize their goals, then the creation of a digital commons-unencumbered by capitalism and its resulting commodification-requires access to reliable, affordable and accessible alternatives to the existing Internet. But this does not necessarily mean either that technological solutions alone will resolve the on-going problem of social and political inequalities. Privacy too must be regulated like a normal good-a public good-as opposed to a commodity that only those with the knowledge or capital can obtain.

\section{References}

About Loomio. 2016. Accessed 8 May 2016. https://www.loomio.org/marketing.

Andrejevic, Mark. 2012. Ubiquitous Surveillance. In The Routledge Handbook of Surveillance Studies, edited by David Lyon and Kristie Ball, 91-98. NY: Routledge.

Andrejevic, Mark. 2011. Surveillance and Alienation in the Online Economy. Surveillance \& Socie ty 8 (3): 278-287.

Ball, Kirstie. 2006. Organization, Surveillance and the Body: Towards a Politics of Resistance. In The orising Surveillance; The Panopticon and Beyond, edited by David Lyon, 296-316. Cullompton: Willan Publishing.

Benkler, Yochai. 2006. The Wealth of Networks: How Social Production Transforms Markets and Freedom. New Haven: Yale University Press.

Bruns, Axel. 2008. Blogs, Wikipedia, Second Life, and Beyond: From Production to Produsage. New York: Peter Lang.

Carillo, Kevin and Chito Okoli. 2008/2009. The Open Source Movement: A Revolution in Software Development. Journal of Computer Information Systems 49 (2): 1-9.

Castells, Manuel. 2011. A Network Theory of Power. International Journal of Communication 5: 773787.

Fuchs, Christian. 2013. Social Media and Capitalism. In Producing the Internet: Critical Perspectives of Social Media, edited by Tobias Olsson. Gothenburg: Nordicom.

Gehl, Robert. 2010. A Cultural and Political Economy of Web 2.0. Doctoral dissertation, George Mason University.

Goodwin, lan. 2012. Power to the People? Web 2.0, Facebook, and DIY Cultural Citizenship in Aoteroa New Zealand. New Zealand Journal of Media Studies 12 (2): 110-134.

Huws, Ursula. 2014. Labor in the Global Digital Economy: The Cybertariat Comes of Age. New York: Monthly Review Press.

Jenkins, Henry. 2006. Convergence Culture, Where Old and New Media Collide. New York: New York University Press.

Lessig, Lawrence. 2006. Code 2.0. New York: Basic Books.

Krause, Alanna. 2015. How to Grow Distributed Leadership. Accessed 21 August 2015. https://medium.com/enspiral-tales/how-to-grow-distributed-leadership-7f6b25f0361c\#.wjt12vovd. 
Krause, Alanna. 2015b. Loomio is Co-Hosting the Open Source / Open Society Conference. Accessed 4 September 2015, http://blog.loomio.org/2015/03/23/osos/.

Krause, Alanna. 2014. Loomio at Personal Democracy Forum 2014. Accessed 11 July 2015. http://blog.loomio.org/2014/08/26/pdf2014/.

Krause, Alanna. 2014b. A Community-Driven Roadmap: Get Involved in Setting the Development. Accessed 19 August 2015. http://blog.loomio.org/2014/06/09/a-community-driven-roadmap-getinvolved-in-setting-the-development-priorities-for-loomio/.

Kuehn, Kathleen M. and Thomas F. Corrigan. 2013. Hope Labor: The Role of Employment Prospects in Online Social Production. Political Economy of Communication 1: 9-25.

Loomio, 2016. Accessed 8 May 2016. http://loomio.org.

Moore, Phoebe and Paul A. Taylor. 2009. Exploitation of the Self in Community-Based Software Production: Workers Freedoms or Firm Foundations? Capital and Class 33 (1): 99-119.

O'Reilly, Tim. 2005. What is Web 2.0? Accessed 29 November 2015. http://www.oreilly.com/pub/a/web2/archive/what-is-web-20.html.

Papacharrissi, Zizi. 2010. Privacy as Luxury Commodity. First Monday, 15:8. Accessed 8 May 2016. http://ojs-prod-lib.cc.uic.edu/ojs/index.php/fm/article/view/3075/2581.

Papacharissi, Zizi. 2009. The Virtual Geographies of Social Networks: A Comparative Analysis of Facebook, Linkedln and A SmallWorld. New Media Society, 11 (1\&2): 199-220.

Raymond, Eric. 1999. The Cathedral and the Bazaar. Knowledge, Technology and Policy 12 (3): 2349.

Ritzer, George J. and Nathan Jurgensen. 2010. Production, Consumption, Prosumption: The Nature of Capitalism in the Age of the Digital Prosumer. Journal of Consumer Culture 10 (1): 13-36.

Sandoval, Marisol. 2016. Fighting Precarity with Co-operation? Worker Co-Operatives in the Cultural Sector. New Formations 88: 51-68.

Scholz, Trebor. 2016. Platform Cooperativism: Challenging the Corporate Sharing Economy. Rosa Luxemburg Foundation.

Siegfried, Alina. 2014. From Occupy to Online Democracy: The Loomio Story. Accessed 27 August 2014. https://www.opendemocracy.net/participation-now/alina-siegfried/from-occupy-to-online$\% 20 \% 20 \% 20 \% 20$ democracy-loomio-story.

Srnicek, Nick and Alex Williams. 2015. Inventing the future: Postcapitalism and a World Without Work. London: Verso.

Terranova, Tiziana. 2004. Network Culture: Politics for the Information Age. London: Pluto Press.

van de Sande, Mathijs. Fighting with Tools: Prefiguration and Radical Politics in the Twenty-

First Century. Rethinking Marxism 27 (2): 177-194.

van Dijck, Jose. Datafication, Dataism and Dataveillance: Big Data Between Scientific Paradigm and Ideology. Surveillance \& Society, 12 (2): 197-208.

Weber, Steven. 2005. The Success of Open Source. Cambridge: Harvard University Press.

\section{About the Authors}

\section{Sam Jackson}

Sam Jackson graduated First-Class Honours in Media Studies from Victoria University of Wellington in 2015. He currently works as a research assistant and independent artist in Wellington, New Zealand.

Kathleen M. Kuehn

Kathleen M. Kuehn is a Lecturer in Media Studies at Victoria University of Wellington. She teaches and researches on the political economy of digital labour, surveillance and consumer culture. Recent publications appear in Political Economy of Communication, Journal of Consumer Culture and International Journal of Communications. She is also the author of the forthcoming book, The Post-Snowden Era: Mass Surveillance and Privacy in New Zealand (BWB Texts, Wellington). 